\title{
Pulmonary arterial hypertension in hereditary hemorrhagic telangiectasia associated with ACVRL1 mutation: a case report
}

\author{
L. J. Walsh ${ }^{1}$ (1) , C. Collins ${ }^{1}$, H. Ibrahim', D. M. Kerins², A. P. Brady ${ }^{3}$ and T. M. O Connor ${ }^{1 *}$
}

\begin{abstract}
Introduction: Hereditary hemorrhagic telangiectasia is an autosomal dominant condition with an estimated prevalence of 1 in 5000. It is characterized by the presence of abnormalities of vascular structures, and may affect many organ systems, including the lungs, brain, spinal cord, gastrointestinal tract, and liver. A causative mutation is identified in approximately $97 \%$ of patients with definite hereditary hemorrhagic telangiectasia in one of three genes including a mutation in endoglin, a mutation in a locus mapped to chromosome 5 , and an activin receptorlike kinase-1 (ACVRL1) mutation that is associated with an increased incidence of primary pulmonary hypertension. Pulmonary arterial hypertension is a rare (15-25 cases per million people) but severe vascular disorder. Heritable pulmonary arterial hypertension is associated with several gene mutations, with $75 \%$ having a mutation in the bone morphogenetic protein receptor 2 (BMPR2). However, the remaining 25\% of patients have other associated genetic mutations including $A C V L R 1$, which is also associated with hereditary hemorrhagic telangiectasia. Pulmonary arterial hypertension is a rare complication in patients with hereditary hemorrhagic telangiectasia $(<1 \%$ of the hereditary hemorrhagic telangiectasia population). We describe a case report with this rare occurrence.

Case presentation: A 70-year-old white/caucasian Irish male presented for screening for hereditary hemorrhagic telangiectasia due to a history of recurrent epistaxis (once/week) and a family history suggestive of pulmonary hypertension. Genetic testing confirmed an ACVRL1 mutation, while an echocardiogram and right heart catheterization confirmed pulmonary arterial hypertension. On examination, he had several mucocutaneous telangiectasia across his face. He was commenced on tadalafil and macitentan. However, this led to increased iron deficiency anemia and pedal edema. Selexipag was also added to his drug regime. He continues to require intermittent admissions for diuresis and blood transfusions.

Conclusion: The association of hereditary hemorrhagic telangiectasia and pulmonary arterial hypertension is rare $(<1 \%)$. Here we describe a case of hereditary hemorrhagic telangiectasia complicated with pulmonary arterial hypertension as a result of an ACVRL 1 mutation. We also describe the clinical challenges of treating these two conditions together, as treatment options for pulmonary arterial hypertension tend to worsen hereditary hemorrhagic telangiectasia symptoms.
\end{abstract}

Keywords: Hereditary hemorrhagic telangiectasia, Pulmonary arterial hypertension, Case report

*Correspondence: toconnor@muh.ie

1 Department of Respiratory Medicine, Mercy University Hospital, Cork, Ireland

Full list of author information is available at the end of the article

\section{Introduction}

Hereditary hemorrhagic telangiectasia (HHT) is an autosomal dominant condition with an estimated prevalence of 1 in 5000 [1]. It is characterized by the presence of abnormalities of vascular structures and may affect original author(s) and the source, provide a link to the Creative Commons licence, and indicate if changes were made. The images or other third party material in this article are included in the article's Creative Commons licence, unless indicated otherwise in a credit line to the material. If material is not included in the article's Creative Commons licence and your intended use is not permitted by statutory regulation or exceeds the permitted use, you will need to obtain permission directly from the copyright holder. To view a copy of this licence, visit http://creativecommons.org/licenses/by/4.0/. The Creative Commons Public Domain Dedication waiver (http://creativeco mmons.org/publicdomain/zero/1.0/) applies to the data made available in this article, unless otherwise stated in a credit line to the data. 
many organ systems, including the lungs, brain, spinal cord, gastrointestinal tract, and liver [1]. Vascular abnormalities include dilation of dermal venules leading to telangiectasia, dilation of post capillary venules, and arteriovenous malformations (AVMs); these abnormalities may result in chronic bleeding, acute hemorrhage, and complications from shunting through AVMs [2-4]. The most common symptom is epistaxis from nasal mucosal telangiectasia, with approximately $90-95 \%$ of patients experiencing epistaxis by adulthood [2].

The Curacao criteria are used to establish a clinical diagnosis of HHT:

1. recurrent and spontaneous epistaxis, which may be mild to severe

2. multiple telangiectasia on the skin of the hands, lips, face, or inside of the nose or mouth

3. AVMs or telangiectasia in one or more internal organs, including the lungs, brain, liver, intestines, stomach, and spinal cord

4. A family history of HHT (first-degree relative with a clinical diagnosis of HHT or a positive genetic test) [5].

The presence of three or more criteria confers a definite diagnosis of HHT, while the presence of two criteria indicates that HHT is possible. If less than two criteria are present, a diagnosis of HHT is unlikely [5].

In $97 \%$ of patients with a definite clinical diagnosis of HHT, a causative mutation is identified in one of three genes, allowing division of HHT into three main groups:

1. HHT1 due to a mutation in endoglin, found on the long arm of chromosome 9, and is associated with a relatively higher number of pulmonary and central nervous system vascular malformations $[6,7]$.

2. HHT2 due to an activin receptor-like kinase-1 (ACVRL1) mutation, on chromosome 12, is associated with an increased incidence of primary pulmonary hypertension.

3. HHT3, which involves a locus mapped to chromosome 5 [8].

Mutations in the SMAD4 gene have also been described in HHT. Patients with this mutation typically also have juvenile intestinal polyposis and should have regular screening colonoscopies for early identification of possible colonic malignancy $[9,10]$. Both the endoglin and ALK-1 genes encode proteins that are predominantly expressed in endothelial cells. Reduced levels of these proteins are associated with impairment of blood vessel wall integrity, causing vessels to be more susceptible to dilation and remodeling during development and repair after injury $[2,6]$.

Pulmonary arterial hypertension (PAH) is a rare (1525 cases per million people) but severe vascular disorder defined by an increased mean pulmonary arterial pressure (PAP) of $\geq 20 \mathrm{mmHg}$ at rest, a pulmonary arterial wedge pressure (PAWP) $\leq 15 \mathrm{mmHg}$, and an increased pulmonary vascular resistance (PVR) of $>3$ Wood units measured by right heart catheterization [11, 12]. Disease onset can occur at any age, but peaks in the third decade of life. PAH is a progressive condition that, if untreated, has a median survival of less than 3 years [13]. Clinical features are nonspecific and include progressive dyspnoea, decreased exercise tolerance, syncope, chest pain, edema, and fatigue, making the diagnosis challenging and often delayed $[5,11]$. PAH can be associated with certain drugs (for example, anorexigens), congenital heart disease with left-to-right shunting leading to Eisenmenger syndrome, connective disease (mainly systemic sclerosis), human immunodeficiency virus, and portal hypertension [11].

Heritable PAH (HPAH) is associated with several gene mutations, with $75 \%$ having a mutation in $B M P R 2$, with a $30 \%$ penetrance [14-16]. However, the remaining $25 \%$ of patients have other associated genetic mutations including ACVLR1, ENG, SMAD4, and BMP9 (also known as $G D F 2$ ), of which the first three are also associated with HHT $[17,18]$. These genes all encode proteins that play a role in the transforming growth factor-beta (TGFB) superfamily signaling pathway [11]. Overall, HHT can be complicated by HPAH, although this is a rare complication $(<1 \%$ of the HHT population) [19]. Here, we describe a case report of one gentleman with this rare occurrence. As this association is rare, we believe this case report will help expand the knowledge of this condition.

\section{Case presentation}

A 70-year-old white/caucasian Irish male, presented for screening for HHT due to a history of recurrent epistaxis (once/week). His grandniece had tragically died suddenly aged 18 months and was found at postmortem to have severe pulmonary hypertension. Genetic testing confirmed an ACVRL1 mutation. The child's mother (patient's niece) and grandfather (patient's brother) were also found to carry this mutation, and both had clinical evidence of HHT (recurrent epistaxis and mucocutaneous telangiectasia), but echocardiography showed normal pulmonary artery pressures for both.

Other relevant past medical history included hypercholesterolemia. He is a never smoker and was active prior to presentation. He reported that his sister had died suddenly aged 36 years while awaiting a heart and 


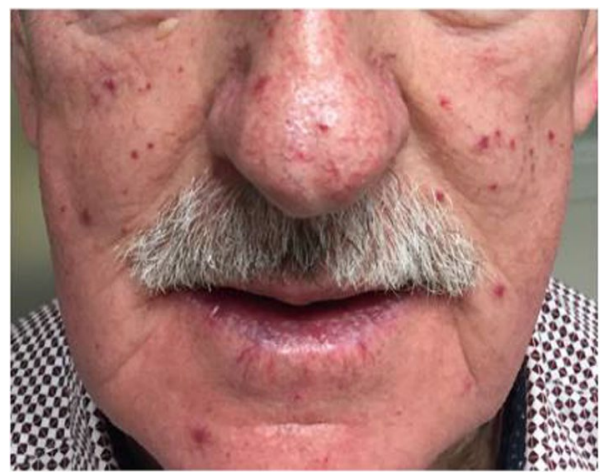

Fig. 1 Evidence of mucocutaneous telangiectasia on face and lips of patient in question. Permission granted to share the picture. The patient gave his written informed consent for his picture to be included in this case report

lung transplant. He has three daughters one of whom also suffers from epistaxis. They have all been referred for genetic assessment. On examination, he had several mucocutaneous telangiectasia across his face (Fig. 1). His chest was clear to auscultation. He had a loud P2 and a murmur consistent with tricuspid regurgitation.

An electrocardiogram demonstrated signs of right axis deviation and right ventricular hypertrophy, while an echocardiography in February 2019 showed flattening of the interventricular cardiac septum consistent with PAH. Following the intravenous administration of agitated saline (a "bubble study"), bubbles were seen in the left ventricle on the eighth cardiac cycle (Fig. 2). The late appearance is consistent with flow across an AVM rather than shunting at an interatrial or interventricular level. The estimated systolic pulmonary arterial pressure was 75-80 mmHg (normal range 18-25 mmHg) (Fig. 3).

A noncontrast computed tomography (CT) thorax showed a main pulmonary artery diameter of $3.6 \mathrm{~cm}$, but no pulmonary AVMs (pAVMs), suggesting either microscopic pAVMs or shunting within other abnormal areas of the lungs accounted for the positive contrast echocardiogram. Multiple liver AVMs were demonstrated on CT thorax, with enlargement of the hepatic artery and distension of the inferior vena cava suggestive of increased venous return. CT pulmonary angiography was also preformed and ruled out chronic pulmonary embolism as a contributing factor to elevated pulmonary pressures. He was subsequently referred to a cardiologist for right heart catheterization, which confirmed severe pulmonary hypertension and elevated pulmonary vascular resistance. His pulmonary artery pressure measured at catheterization was $77 / 34 \mathrm{mmHg}$, wedge pressure was $4 \mathrm{mmHg}$, and pulmonary vascular resistance was 9.64 Wood units.

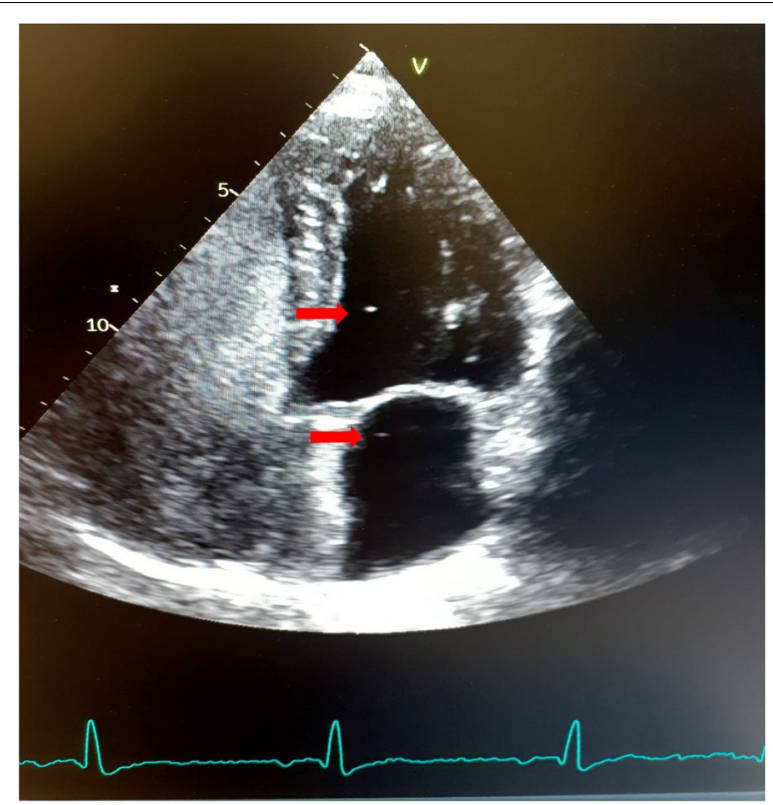

Fig. 2 Echocardiogram (May 2019) that shows several bubbles in the left heart, eight cardiac cycles after the injection of agitated saline. This indicated that pulmonary arteriovenous malformations are likely present. Bubbles highlighted by red arrows

A brain magnetic resonance imaging (MRI) ruled out any cranial AVMs but did show increased T1 hyperintensities in the basal ganglia bilaterally. These MRI changes are said to occur in HHT patients, mainly males, and are thought to arise from manganese deposits as a result of hepatic AVMs [20].

Pulmonary function tests showed a forced vital capacity of $3.46 \mathrm{~L}$ (87.85\% predicted), forced expiratory volume of $2.72 \mathrm{~L}$ (90.78\% predicted), total lung volume of $7 \mathrm{~L}$ (100.9\%), diffusing capacity of the lungs for carbon monoxide (DLCO) of $24.06 \mathrm{~mL} / \mathrm{min} / \mathrm{mm}$ ( $94.74 \%$ predicted), and vital capacity of $3.42 \mathrm{~L}$ (87.34\% predicted).

Following confirmation of PAH, he was commenced on tadalafil $40 \mathrm{mg}$ once a day (OD), a phosphodiesterase type 5 inhibitor, and macitentan $10 \mathrm{mg}$ OD, a dual endothelin receptor antagonist. He developed a slight increase in the frequency of epistaxis thought to be secondary to tadalafil, and mild bipedal edema, thought to be secondary to macitentan, which responded to low-dose diuretic therapy. Six months after initiation of therapy for pulmonary hypertension, he began to develop symptomatic iron-deficiency anemia [hemoglobin (Hb) $9.1 \mathrm{~g} / \mathrm{dL}$ ], again thought to be a side-effect of macitentan, which responded to intermittent blood and iron transfusions as well as oral iron replacement. Just over a year post diagnosis, he developed worsening dyspnoea and bipedal edema and was treated with increased diuretics. To prevent further episodes of right heart failure, a prostacyclin 


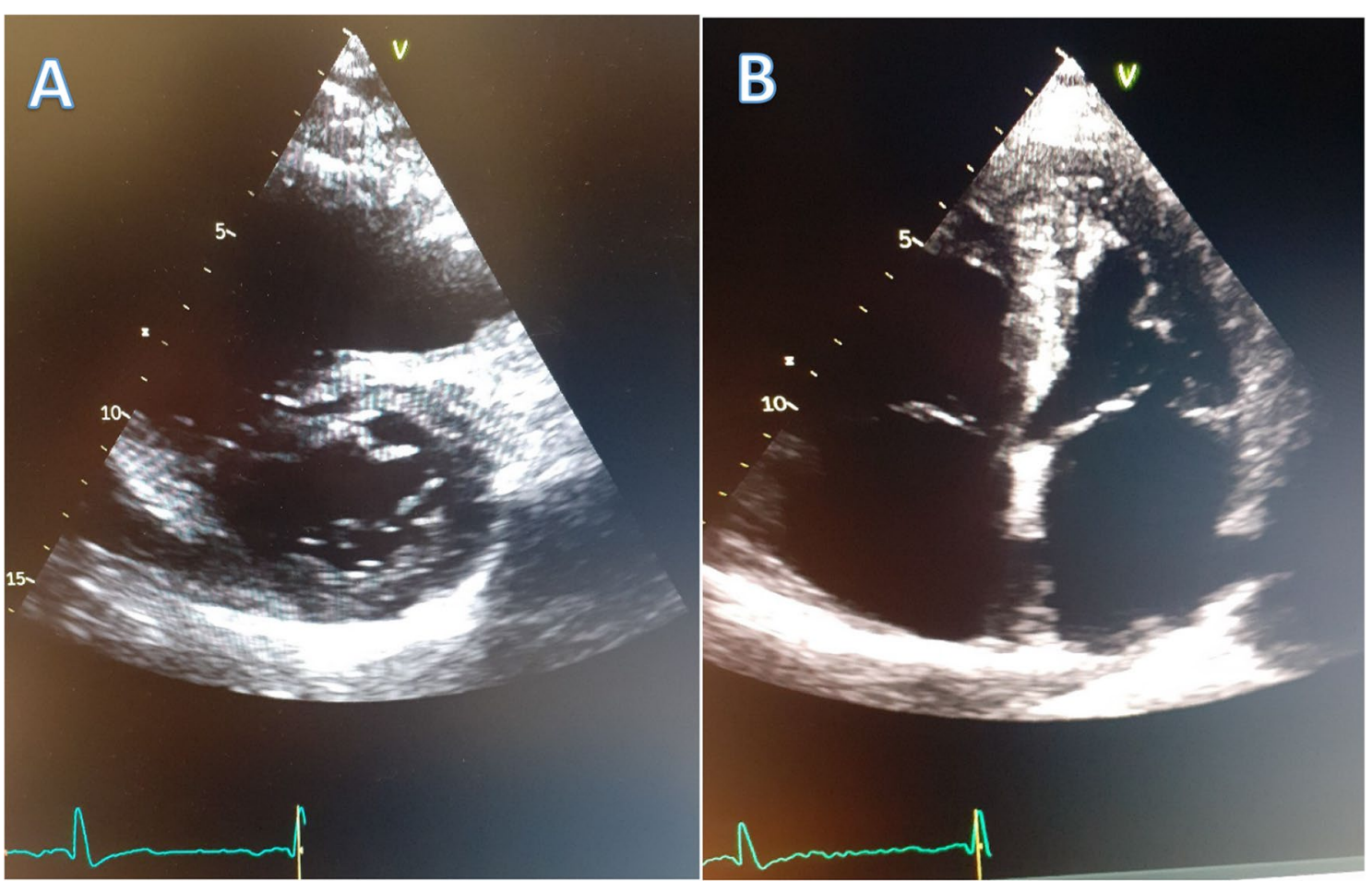

Fig. 3 Echocardiogram evidence of right ventricular hypertrophy $(\mathbf{A})$ and of right atrial enlargement $(\mathbf{B})$ both consistent with underlying pulmonary arterial hypertension

receptor agonist, selexipag 200 mcg twice a day (BD) was added to his drug regime. His brain natriuretic protein (BNP) in May 2020 was $169 \mathrm{pg} / \mathrm{mL}$. He continues to require intermittent admissions every 6-8 weeks for diuresis and anemia, but is otherwise symptomatically well.

\section{Discussion}

Pulmonary arterial hypertension (PAH) is a rare but severe complication of HHT, with a prevalence of $<1 \%$ of cases [21]. ACVRL1 mutations have been recognized to lead to a combination of HHT and PAH for several years [11]. In many of these patients, PAH was diagnosed before the clinical symptoms of HHT manifested. However, most family members of HHT patients with PAH will not develop PAH, which may indicate that additional genetic or environmental factors may be necessary to develop the HPAH phenotype [22]. PAH and HHT together have been shown to lead to worse outcomes than PAH alone, despite similar therapy and hemodynamics at time of diagnosis [22]. Compared with BMPR2 mutation carriers and those with idiopathic PAH, ACVRL1 mutation carriers are diagnosed at a younger age [22]. This suggests that the disease progresses more rapidly with more severe consequences. Li et al. [19] compared nine HHT-PAH (mutation unknown) patients to 18 idiopathic pulmonary arterial hypertension (IPAH) patients and found that 1- and 3-year survival rates were $78 \%$ and $53 \%$ for HHT-PAH patients, respectively, which was significantly lower than patients with IPAH (1- and 3 -year survival $91 \%$ and $74 \%, p=0.047$ ).

Management of HHT and PAH together can be quite difficult as the side effects of treatment of $\mathrm{PAH}$ can worsen the symptoms of HHT. Results from the SERAPHIN trial showed that although macitentan was effective in improving 6-minute walk distance and reducing mortality and morbidity, there was an increase in anemia among those treated when compared with placebo [23]. Given that HHT also contributes to anemia, this can be a fine balancing act. The patient in this case did suffer greatly with worsening iron deficiency anemia since starting treatment. Furthermore, the OPTIMA study was a prospective, multicenter, single-arm, open-label phase IV study that explored the efficacy and safety of macitentan administered as initial oral combination therapy with tadalafil in newly diagnosed, treatment-naïve $\mathrm{PAH}$ patients. This study found that the most frequent adverse events with this drug combination were peripheral edema (28.3\%), headache $(23.9 \%)$, diarrhoea (19.6\%), dyspnoea (15.2\%), anemia (13.0\%), and asthenia (13.0\%) [24]. This study was in line with previously reported data $[23,25$, 26]. With regards to worsening of bleeding seen with the use of macitentan in HHT and PAH patients, there 
is some evidence that bevacizumab can reduce the incidence of gastrointestinal bleeds [27-29]. Overall, there is a paucity of data relating to the treatment of HHT and $\mathrm{PAH}$ together, which makes this sensitive balancing act even more difficult.

Some of the strengths of this case report include that PAH was diagnosed on right heart catheter, which is often not the case in other reports due to the severity of patient disease [30]. This case describes the challenges involved in treatment of HHT and PAH together. A limitation of this study is that we do not have the genetic results from the patient's daughters currently available.

\section{Conclusion}

We present a case report of PAH and HHT occurring in a gentleman as a result of an $A C V R L 1$ mutation. This is a rare association in HHT patients. Furthermore, this case highlights the difficulty in treating PAH in HHT patients as treatment, such as in this case, can worsen symptoms of HHT. This case report also highlights the importance of performing an echocardiogram in patients with an ACVRL1 mutation as this mutation is associated with a worse overall prognosis when compared with others or to IPAH.

\begin{abstract}
Abbreviations
ACVRL 1: Activin receptor-like kinase-1; AVMs: Arteriovenous malformations; BMPR2: Bone morphogenetic protein receptor 2; BNP: Brain natriuretic protein; $\mathrm{HHT}$ : Hereditary hemorrhagic telangiectasia; HPAH: Hereditary pulmonary arterial hypertension; IPAH: Idiopathic pulmonary arterial hypertension; PAH: Pulmonary arterial hypertension; PAP: Pulmonary arterial pressure; PAWP: Pulmonary arterial wedge pressure; PVR: Pulmonary vascular resistance; TGF- $\beta$ : Transforming growth factor-beta.
\end{abstract}

\section{Acknowledgements}

Not applicable.

\section{Authors' contributions}

LJW researched and wrote the case together with $\mathrm{CC}$ and $\mathrm{HI}$. TOC proposed the idea for the case and was the primary editor of the paper. DMK is a cardiologist involved in the diagnosis and management of the patients PAH and contributed echocardiogram photographs for use in case report. APB helped edit the case. All authors read and approved the final manuscript.

\section{Funding}

No funding was sought or used in this case report.

\section{Availability of data and materials}

All data generated or analyzed during this study are included in this published article

\section{Declarations}

Ethics approval and consent to participate Not applicable.

\section{Consent for publication}

Written informed consent was obtained from the patient for publication of this case report and any accompanying images. A copy of the written consent is available for review by the Editor-in-Chief of this journal.

\section{Competing interests}

There are no competing interests for any of the contributing authors

\section{Author details}

${ }^{1}$ Department of Respiratory Medicine, Mercy University Hospital, Cork, Ireland. ${ }^{2}$ Department of Cardiology, Mercy University Hospital, Cork, Ireland. ${ }^{3}$ Department of Radiology, Mercy University Hospital, Cork, Ireland.

Received: 6 July 2021 Accepted: 28 January 2022

Published online: 01 March 2022

\section{References}

1. Ryan DJ, O'Connor TM, Murphy MM, Brady AP. Follow-up interval for small untreated pulmonary arteriovenous malformations in hereditary haemorrhagic telangiectasia. Clin Radiol. 2017;72(3):236-41.

2. Brady AP, Murphy MM, O'Connor TM. Hereditary haemorrhagic telangiectasia: a cause of preventable morbidity and mortality. Ir J Med Sci. 2009;178(2):135-46.

3. Faughnan ME, Palda VA, Garcia-Tsao G, Geisthoff UW, McDonald J, Proctor DD, HHT Foundation International_Guidelines Working Group, et al. International guidelines for the diagnosis and management of hereditary haemorrhagic telangiectasia. J Med Genet. 2011;48(2):73-87.

4. Guttmacher AE, Marchuk DA, White RI Jr. Hereditary haemorrhagic telangiectasia. N Engl J Med. 1995;333(14):918-24.

5. Shovlin CL, Guttmacher AE, Buscarini E, Faughnan ME, Hyland RH, Westermann CJ, et al. Diagnostic criteria for hereditary haemorrhagic telangiectasia (Rendu-Osler-Weber syndrome). Am J Med Genet. 2000;91:66e7.

6. Shovlin CL, Letarte M. Hereditary haemorrhagic telangiectasia and pulmonary arteriovenous malformations: issues in clinical management and review of pathogenic mechanisms. Thorax. 1999;54:714-29.

7. Saluja S, Henderson KJ, White RI. Embolotherapy in the bronchial and pulmonary circulations. Radiol Clin N Am. 2000;38:425-48.

8. Cole SG, Begbie ME, Wallace GMF, Shovlin CL. A new locus for hereditary haemorrhagic telangiectasia HHT3 maps to chromosome 5. J Med Genet. 2005:42:577-82.

9. Gallione CJ, Repetto GM, Legius E, Rustgi AK, Schelley SL, Tejpar S, et al. A combined syndrome of juvenile polyposis and hereditary haemorrhagic telangiectasia associated with mutations in MADH4 (SMAD4). Lancet. 2004:363:852-9.

10. Gallione CJ, Richards JA, Letteboer TG, Rushlow D, Prigoda NL, Leedom TP, et al. SMAD4 mutations found in unselected HHT patients. J Med Genet. 2006:43:793-7.

11. Vorselaars VMM, Hosman AE, Westermann CJJ, Snijder RJ, Mager JJ, Goumans MJ, Post MC. Pulmonary arterial hypertension and hereditary haemorrhagic telangiectasia. Int J Mol Sci. 2018;19:3203.

12. Simonneau G, Montani D, Celermajer DS, Denton CP, Gatzoulis MA, Krowka M, et al. Haemodynamic definitions and updated clinical classification of pulmonary hypertension. Eur Respir J. 2019;53:1801913.

13. Alonzo GE, Barst RJ, Ayres SM, Bergofsky EH, Brundage BH, Detre KM, et al. Survival in patients with primary pulmonary hypertension: results from a national prospective registry. Ann Intern Med. 1991;115:343-9.

14. Soubrier F, Chung WK, Machado R, Grunig E, Aldred M, Geraci M, et al. Genetics and genomics of pulmonary arterial hypertension. J Am Coll Cardiol. 2013:62:D13-21.

15. Larkin EK, Newman JH, Austin ED, Hemnes AR, Wheeler L, Robbins IM, et al. Longitudinal analysis casts doubt on the presence of genetic anticipation in heritable pulmonary arterial hypertension. Am J Respir Crit Care Med. 2012;186:892-6.

16. Graf S, Haimel M, Bleda M, Hadinnapola C, Southgate L, Li W, et al. Identification of rare sequence variation underlying heritable pulmonary arterial hypertension. Nat Commun. 2018;9:1416.

17. Tillet E, Bailly S. Emerging roles of BMP9 and BMP10 in hereditary haemorrhagic telangiectasia. Front Genet. 2015;5:456. 
18. Wang G, Fan R, Ji R, Zou W, Penny DJ, Varghese NP, Fan Y. Novel homozygous BMP9 nonsense mutation causes pulmonary arterial hypertension: a case report. BMC Pulm Med. 2016;16:17.

19. Li W, Xiong C-M, Gu Q, Wang X-T, Cheng XI, Huang L, et al. The clinical characteristics and long-term prognosis of pulmonary arterial hypertension associated with hereditary haemorrhagic telangiectasia. Pulm Circ. 2018:8(2):1-11.

20. Serra MM, Besada CH, Cabana Cal A, Saenz A, Stefani CV, Bauso D, et al. Central nervous system manganese induced lesions and clinical consequences in patients with hereditary hemorrhagic telangiectasia. Orphanet J Rare Dis. 2017;12(1):92.

21. Faughnan ME, Granton JT, Young LH. The pulmonary vascular complications of hereditary haemorrhagic telangiectasia. Eur Respir J. 2009;33:1186-94.

22. Girerd B, Montani D, Coulet F, Sztrymf B, Yaici A, Jais X, et al. Clinical outcomes of pulmonary arterial hypertension in patients carrying an ACVRL1 (ALK1) mutation. Am J Respir Crit Care Med. 2010;181:851-61.

23. Pulido T, Adzerikho I, Channick RN, Delcroix M, Galiè N, Ghofrani HA, SERAPHIN Investigators, et al. Macitentan and morbidity and mortality in pulmonary arterial hypertension. N Engl J Med. 2013:369(9):809-18.

24. Sitbon O, Cottin V, Canuet M, Clerson P, Gressin V, Perchenet L, et al. Initial combination therapy of macitentan and tadalafil in pulmonary arterial hypertension. Eur Respir J. 2020;56:2000673.

25. Jansa P, Pulido T. Macitentan in pulmonary arterial hypertension: a focus on combination therapy in the SERAPHIN trial. Am J Cardiovasc Drugs. 2018;18:1-11.

26. Chin KM, Channick R, Kim NH, Muros-Le Rouzic E, Selej M, McLaughlin V. OPUS registry: treatment patterns with macitentan in patients with pulmonary arterial hypertension. Am J Crit Care Med. 2017;195:A2299.

27. Kanellopoulou T, Alexopoulou A. Bevacizumab in the treatment of hereditary haemorrhagic telangiectasia. Expert Opin Biol Ther. 2013;13(9):1315-23.

28. Lupu A, Stefanescu C, Treton X, Attar A, Corcos O, Bouhnik Y. Bevacizumab as rescue treatment for severe recurrent gastrointestinal bleeding in hereditary haemorrhagic telangiectasia. J Clin Gastroenterol. 2013;47(3):256-7.

29. Dupuis-Girod S, Ginon I, Saurin JC, Marion D, Guillot E, Decullier E, et al. Bevacizumab in patients with hereditary haemorrhagic telangiectasia and severe hepatic vascular malformations and high cardiac output. JAMA. 2012;307(9):948-55.

30. Wu J, Yuan Y, Wang X, Shao DY, Liu LG, He J, Li P. Pulmonary arterial hypertension in a patient with hereditary haemorrhagic telangiectasia and family gene analysis: a case report. World J Clin Cases. 2021;9(13):3079-89.

\section{Publisher's Note}

Springer Nature remains neutral with regard to jurisdictional claims in published maps and institutional affiliations.

Ready to submit your research? Choose BMC and benefit from:

- fast, convenient online submission

- thorough peer review by experienced researchers in your field

- rapid publication on acceptance

- support for research data, including large and complex data types

- gold Open Access which fosters wider collaboration and increased citations

- maximum visibility for your research: over $100 \mathrm{M}$ website views per year

At BMC, research is always in progress.

Learn more biomedcentral.com/submissions 